\title{
Impact of permissive hypercapnia on regional cerebral oxygen saturation and postoperative cognitive function in patients undergoing cardiac valve replacement
}

\author{
Longchang Zhu ${ }^{1,2} \wedge$, Hongwei Shi ${ }^{1}$, Cheng Zhu ${ }^{1}$, Hanyu Liu ${ }^{1}$, Zhonghong Su${ }^{1}$, Yamei Zhao ${ }^{1}$ \\ ${ }^{1}$ Department of Anesthesiology, Nanjing Frist Hospital, Nanjing Medical University, Nanjing, China; ${ }^{2}$ Department of Anesthesiology, The Third \\ People's Hospital of Kunshan, Kunshan, China \\ Contributions: (I) Conception and design: L Zhu, H Shi; (II) Administrative support: H Shi; (III) Provision of study materials or patients: L Zhu, C \\ Zhu, Z Su; (IV) Collection and assembly of data: Y Zhao, H Liu; (V) Data analysis and interpretation: L Zhu; (VI) Manuscript writing: All authors; \\ (VII) Final approval of manuscript: All authors. \\ Correspondence to: Hongwei Shi. Department of Anesthesiology, Nanjing Frist Hospital, Nanjing Medical University, Nanjing 210006, China. \\ Email: mdshw@163.com.
}

\begin{abstract}
Backgroundi Cardiac valve replacement (CVR) is currently the main surgical treatment for patients with valvular heart diseases (VHD). Postoperative cognitive dysfunction (POCD) is one of the most serious complications of cardiac surgery.. Permissive hypercapnia (PHC), an important lung-protective ventilation strategy, has protective effects on vital organs, including the heart, lungs, and central nervous system (CNS). The main objective of this study is to assess the effect of the $\mathrm{PHC}$ ventilation strategy on $\mathrm{rSO}_{2}$ and postoperative cognitive function in patients undergoing CVR.

Methods: A total of 66 patients undergoing CVR were included and randomly divided into the PHC ventilation group (Group H, n=33) and conventional ventilation group (Group C, n=33). Patients of both groups were subjected to conventional ventilation before cardiopulmonary bypass (CPB). patients in Group $\mathrm{H}$ were subjected to the $\mathrm{PHC}$ ventilation strategy to keep the partial pressure of carbon dioxide $\left(\mathrm{PaCO}_{2}\right)$ at 46-60 mmHg.

Results: (I) Group H had a lower HR at T0 and T1 $(\mathrm{P}<0.05)$ and higher CO at T3 and T4 $(\mathrm{P}<0.05)$ than Group C. (II) Group $\mathrm{H}$ had higher $\mathrm{rSO}_{2}$ at $\mathrm{T} 4(\mathrm{P}<0.05)$, lower $\mathrm{pH}$ and lactate $(\mathrm{Lac})$ at $\mathrm{T} 4(\mathrm{P}<0.05)$, higher $\mathrm{PaCO}_{2}$ at $\mathrm{T} 3$ and $\mathrm{T} 4(\mathrm{P}<0.05)$, and lower $\mathrm{PaO}_{2}$ at $\mathrm{T} 3$ and $\mathrm{T} 4(\mathrm{P}<0.05)$. (III) Compared to $1 \mathrm{~d}$ before surgery, the MMSE scores of both groups were lower $24 \mathrm{~h}$ after surgery $(\mathrm{P}<0.05)$.

Conclusions: PHC can increase the $\mathrm{rSO}_{2}$ of patients undergoing CVR, increase cerebral blood flow, improve the cerebral oxygen supply/consumption balance, and play a protective role in the brain. It has no significant impact on the incidence of POCD.
\end{abstract}

Koywords: Permissive hypercapnia; cardiac valve replacement; regional cerebral oxygen saturation; postoperative cognitive dysfunction

Submitted Sep 14, 2020. Accepted for publication Nov 19, 2020.

doi: 10.21037/apm-20-2090

View this article at: http://dx.doi.org/10.21037/apm-20-2090

\footnotetext{
^ ORCID: 0000-0002-9095-8508.
} 


\section{Introduction}

Postoperative cognitive dysfunction (POCD) is a common complication after cardiac surgery, occurring in $23-81 \%$ of patients undergoing cardiac surgery. Factors including cerebral embolism and hypoperfusion during cardiac surgery and nonpulsatile blood flow during cardiopulmonary bypass (CPB) may all lead to POCD (1). POCD has become a research hotspot in the recent years since it seriously impacts prognosis and postoperative quality of life. Permissive hypercapnia (PHC) is a lungprotective ventilation strategy whose efficacy has been proven in recent years. This method can improve patients' cerebral oxygen metabolism and reduce the incidence of POCD, playing a protective and anti-inflammatory role in vital organs, including the heart and central nervous system (CNS) $(2,3)$.

In recent years, near-infrared spectroscopy (NIRS) has been widely used to monitor regional cerebral oxygen saturation $\left(\mathrm{rSO}_{2}\right)$ during surgical anesthesia since a decrease in cerebral oxygen saturation is associated with hypotension or cerebral anoxia during organ reperfusion (4). This study aimed to investigate the impact of the $\mathrm{PHC}$ ventilation strategy on $\mathrm{rSO}_{2}$ and postoperative cognitive function in patients undergoing cardiac valve replacement (CVR).

We present the following article in accordance with the CONSORT reporting checklist (available at http://dx.doi. org/10.21037/apm-20-2090).

\section{Methods}

\section{Clinical data}

A total of 66 patients undergoing CVR between January 2019 and March 2019 in our hospital were enrolled in this study, including 31 males and 35 females, with an age range of 40-74 years and American Society of Anesthesiologists class II or III. The patients were randomly divided into the PHC ventilation group (Group $\mathrm{H}$ ) and conventional mechanical ventilation group (Group C) using a random number table. Inclusion criteria were as follows: the patient was scheduled to undergo CVR, had no surgical contraindications, was conscious and able to think independently, and had no diseases causing elevated intracranial pressure, such as cerebral hemorrhage; and the patient had a cardiac function grade $\leq$ III and a left ventricular ejection fraction (LVEF) $\geq 45 \%$. Exclusion criteria were as follows: history of cranial cerebral trauma surgery; history of cerebral infarction, stroke, or other CNS diseases; severe diseases of vital organs, such as the liver or kidney; mental diseases or poor consciousness; and inability to undergo neuropsychological assessments due to severe visual or hearing impairment. The study was conducted in accordance with the Declaration of Helsinki (as revised in 2013). This study was approved by the ethics committee of our hospital (No. kssy2019-30). Each patient understood this study and voluntarily signed an informed consent form.

\section{Anesthesia monitoring}

After the patient entered the operating room, a peripheral venous access was established, and a face mask was given for oxygen. The patient was routinely monitored for electrocardiography, pulse oximetry, heart rate (HR), and noninvasive blood pressure, and the invasive arterial blood pressure was continuously monitored through radial arterial puncture under local anesthesia. The left forehead $\mathrm{rSO}_{2}$ was monitored by NIRS (Covidien INVOS 5100C). The consciousness index (cerebral state index, CSI) was continuously monitored by an anesthesia depth monitor (Danmeter, Denmark). After tracheal intubation, an 8.5-Fr double-lumen central venous catheter was placed into the right internal jugular vein, and the central venous pressure (CVP) was monitored. Cardiac function was monitored by transesophageal echocardiography, and cardiac output (CO) was measured by color Doppler flow imaging through the left ventricular outflow tract.

\section{Anesthesia induction and maintenance}

Anesthesia was induced by $0.05 \mathrm{mg} / \mathrm{kg}$ midazolam, $0.8 \mu \mathrm{g} / \mathrm{kg}$ sufentanil, 1-2 $\mathrm{mg} / \mathrm{kg}$ propofol, and $0.2 \mathrm{mg} / \mathrm{kg}$ cisatracurium besylate. After tracheal intubation, the patient was subjected to intermittent positive-pressure breathing, with the tidal volume at $8-10 \mathrm{~mL} / \mathrm{kg}$, inspiratory:expiratory (I:E) ratio $=1: 2$, breathing rate at $10-12$ breaths $/ \mathrm{min}$, and fraction of inspired oxygen $\left(\mathrm{FiO}_{2}\right)$ at $70 \%$. The end-tidal carbon dioxide $\left(\mathrm{P}_{\mathrm{ET}} \mathrm{CO}_{2}\right)$ was maintained at $35-45 \mathrm{mmHg}$. Anesthesia was maintained in both groups by $0.2-$ $0.4 \mu \mathrm{g} \cdot \mathrm{kg}^{-1} \cdot \mathrm{min}^{-1}$ remifentanil, $0.2-0.3 \mathrm{mg} \cdot \mathrm{kg}^{-1} \cdot \mathrm{h}^{-1}$ cisatracurium besylate, and $3-4 \mathrm{mg} \cdot \mathrm{kg}^{-1} \cdot \mathrm{h}^{-1}$ propofol through an intravenous infusion pump. During the surgery, an appropriate amount of sufentanil was intermittently injected intravenously at $0.5-1.0 \mu \mathrm{g} / \mathrm{kg}$. The CSI (anesthesia depth) was maintained between 40 and 60 . 
Table 1 Comparison of general information between the two groups $(\mathrm{n}=33, \bar{x} \pm \mathrm{s})$

\begin{tabular}{lccccccc}
\hline Group & Age (years) & Body weight $(\mathrm{kg})$ & BSA $\left(\mathrm{m}^{2}\right)$ & $\begin{array}{c}\text { NYHA classification } \\
(\mathrm{n}, \mathrm{II} / \mathrm{II})\end{array}$ & ACCT (min) & CPB duration (min) & Surgery duration (min) \\
\hline Group C & $60.27 \pm 9.19$ & $63.94 \pm 11.46$ & $1.66 \pm 0.19$ & $23 / 10$ & $79.06 \pm 27.56$ & $109.45 \pm 37.18$ \\
Group H & $61.52 \pm 7.97$ & $64.32 \pm 12.08$ & $1.70 \pm 0.19$ & $26 / 7$ & $71.64 \pm 20.45$ & $101.15 \pm 27.26$ & $221.21 \pm 43.61$ \\
\hline
\end{tabular}

BSA, body surface area; NYHA, New York Heart Association; ACCT, aortic cross-clamping time; CPB, cardiopulmonary bypass.

\section{Ventilation mode management}

Respiratory parameter settings and implementation of PHC: (I) Group C: after CPB was stopped, the patient continued to receive conventional mechanical ventilation with the tidal volume at $8-10 \mathrm{~mL} / \mathrm{kg}, \mathrm{I}: \mathrm{E}=1: 2$, and respiratory rate at $10-12 / \mathrm{min}$. The respiratory parameters were adjusted based on the difference between $\mathrm{P}_{\mathrm{ET}} \mathrm{CO}_{2}$ and the arterial partial pressure of carbon dioxide $\left(\mathrm{PaCO}_{2}\right)$, so that $\mathrm{PaCO}_{2}$ was kept at $35-45 \mathrm{mmHg}$. (II) Group H: thirty minutes after stopping $\mathrm{CPB}$ and when the circulation function was stable, the patient was subjected to PHC ventilation with the tidal volume of $6-8 \mathrm{~mL} / \mathrm{kg}, \mathrm{I}: \mathrm{E}=1: 2$, $\mathrm{FiO}_{2}=70 \%$, and respiratory rate $10-15 / \mathrm{min}$. During the surgery, the respiratory parameters were adjusted based on the difference between $\mathrm{P}_{\mathrm{ET}} \mathrm{CO}_{2}$ and $\mathrm{PaCO}_{2}$, so that $\mathrm{PaCO}_{2}$ was maintained at $46-60 \mathrm{mmHg}$. With $\mathrm{CPB}, \mathrm{PaCO}_{2}$ was maintained at $35-45 \mathrm{mmHg}$ according blood gas analysis.

\section{Indicator recording}

The HR, mean arterial pressure (MAP), $\mathrm{CO}, \mathrm{rSO}_{2}$ and other indicators were recorded at five time points: before induction of anesthesia (T0), before chest opening (T1), 30 min into the CPB (T2), $30 \mathrm{~min}$ after CPB (T3), and at suture (T4). Blood samples were collected from the radial artery at the above time points for blood gas analysis, and the $\mathrm{pH}, \mathrm{PaCO}_{2}, \mathrm{PaO}_{2}$, lactate (Lac), and blood glucose levels were recorded. The Mini-Mental State Examination (MMSE) score was recorded $1 \mathrm{~d}$ before surgery and $24 \mathrm{~h}$ and $7 \mathrm{~d}$ after surgery. Patients with a postoperative MMSE 2 points lower than baseline were diagnosed with POCD. All tests were completed by the same physician.

\section{Statistical analysis}

Calculation of sample size: Stata software was used for power analysis. The lower limit for normal $\mathrm{rSO}_{2}$ was 60 (\%), and a 5-percentage-point increase in $\mathrm{rSO}_{2}$ (to 65\%) was clinically significant. The standard deviation was 7 (\%), with alpha $=0.05$ and power $=0.8$. Calculations showed that the sample size of each group needed to be 31 . Data were analyzed by SPSS 21.0 statistical software. Qualitative data are expressed as percentages, and the chi-squared test was used for comparison between groups. Quantitative data conforming to a normal distribution are expressed as $\bar{x} \pm s$. The independent-sample $t$-test was used for comparison between the control group and experimental group. Repeated-measures analysis of variance (ANOVA) was used for intragroup comparisons at different time points. $\mathrm{P}<0.05$ indicates that the difference was statistically significant.

\section{Results}

This study included a total of 66 patients, 33 in each group. No significant differences in the age, body weight, body surface area (BSA), New York Heart Association (NYHA) classification, aortic cross-clamping time (ACCT), CPB duration, or surgery duration were detected between the two groups $(\mathrm{P}>0.05$, Table 1$)$.

\section{Comparison of hemodynamic parameters at each time point between the two groups}

Group H had a lower HR at T0 and T1 $(\mathrm{P}<0.05)$ and higher $\mathrm{CO}$ at $\mathrm{T} 3$ and $\mathrm{T} 4$ than Group $\mathrm{C}(\mathrm{P}<0.05)$. Inter- and intragroup comparisons of other hemodynamic parameters did not show any statistically significant differences $(\mathrm{P}>0.05)$ (Table 2).

\section{Comparison of $\mathrm{SSO}_{2}$ and relevant indicators at each time point between the two groups}

Group $\mathrm{H}$ had higher $\mathrm{rSO}_{2}$ at $\mathrm{T} 4(\mathrm{P}<0.05)$, lower $\mathrm{pH}$ and Lac at T4 $(\mathrm{P}<0.05)$, higher $\mathrm{PaCO}_{2}$ at $\mathrm{T} 3$ and $\mathrm{T} 4(\mathrm{P}<0.05)$, and lower $\mathrm{PaO}_{2}$ at T3 and T4 than Group $\mathrm{C}(\mathrm{P}<0.05)$. Intergroup comparisons of other relevant data did not show any statistically significant differences $(\mathrm{P}>0.05)$ (Table 3, and Figures 1-3). 
Table 2 Comparison of hemodynamic parameters at each time point between the two groups $(\mathrm{n}=33, \bar{x} \pm \mathrm{s})$

\begin{tabular}{|c|c|c|c|c|c|c|c|}
\hline Indicator & Group & $\mathrm{n}$ & TO & $\mathrm{T} 1$ & $\mathrm{~T} 2$ & T3 & $\mathrm{T} 4$ \\
\hline HR (times/min) & Group H & 33 & $78.36 \pm 16.49^{b}$ & $67.79 \pm 11.58^{\mathrm{ab}}$ & - & $87.42 \pm 6.93^{q}$ & $86.45 \pm 8.07$ \\
\hline \multirow[t]{2}{*}{ MAP (mmHg) } & Group C & 33 & $91.64 \pm 15.43$ & $77.88 \pm 12.43^{\mathrm{a}}$ & $64.00 \pm 3.30^{\mathrm{b}}$ & $72.06 \pm 4.96^{a}$ & $72.97 \pm 4.38^{a}$ \\
\hline & Group H & 33 & $87.94 \pm 13.92$ & $73.18 \pm 7.70^{a}$ & $64.36 \pm 4.66^{\mathrm{b}}$ & $72.52 \pm 5.35^{\mathrm{a}}$ & $72.76 \pm 4.58^{\mathrm{a}}$ \\
\hline CVP (mmHg) & Group H & 33 & - & $7.27 \pm 2.50$ & - & $9.36 \pm 2.26^{\mathrm{a}}$ & $9.21 \pm 2.67^{\mathrm{a}}$ \\
\hline \multirow[t]{2}{*}{$\mathrm{CO}(\mathrm{L} / \mathrm{min})$} & Group C & 33 & - & $3.51 \pm 1.50$ & $4.25 \pm 0.65^{\mathrm{a}}$ & $4.72 \pm 1.47^{\mathrm{a}}$ & $4.67 \pm 1.40^{a}$ \\
\hline & Group H & 33 & - & $4.03 \pm 1.67$ & $4.46 \pm 0.47$ & $5.69 \pm 1.71^{\mathrm{ab}}$ & $5.48 \pm 1.62^{b}$ \\
\hline
\end{tabular}

${ }^{a}, \mathrm{P}<0.05$ compared to T0; ${ }^{\mathrm{b}}, \mathrm{P}<0.05$ compared to Group C; -, no data. MAP, mean arterial pressure; CVP, central venous pressure; CO, cardiac output.

Table 3 Differences in cerebral oxygen metabolism and relevant indicators at each time point in the two groups $(n=33, \bar{x} \pm s)$

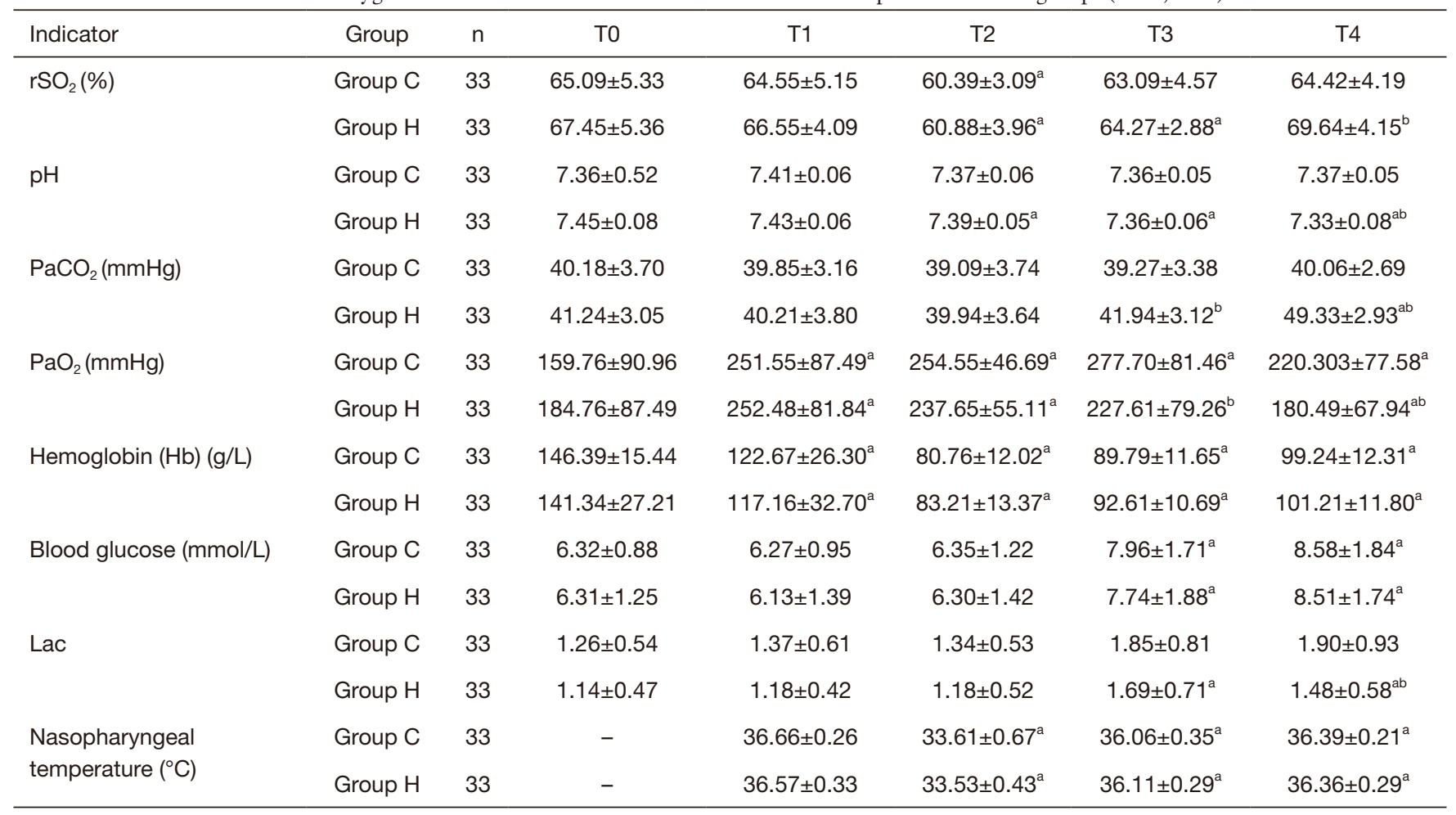

a, $\mathrm{P}<0.05$ compared to $\mathrm{TO} ;{ }^{\mathrm{b}}, \mathrm{P}<0.05$ compared to Group $\mathrm{C} ;-$, data not measured. $\mathrm{rSO}_{2}$, regional cerebral oxygen saturation; $\mathrm{pH}$, pondus hydrogenii; $\mathrm{PaCO}_{2}$, partial pressure of carbon dioxide; $\mathrm{PaO}_{2}$, partial pressure of oxygen. Lac, lactic acid.

\section{Comparison of MMSE scores at each time point between the two groups}

Compared to their MMSE scores $1 \mathrm{~d}$ before the surgery, the MMSE scores at $24 \mathrm{~h}$ after surgery decreased in both groups $(\mathrm{P}<0.05)$. Group H had a higher MMSE score than Group C
$24 \mathrm{~h}$ after surgery $(\mathrm{P}<0.05)$ (Table 4 and Figure 4$)$. Compared to that at $1 \mathrm{~d}$ before surgery, the incidence of POCD in each group of patients differed significantly at $24 \mathrm{~h}$ after surgery $(\mathrm{P}<0.05)$. The POCD incidence also differed significantly between the two groups at $24 \mathrm{~h}$ after surgery 


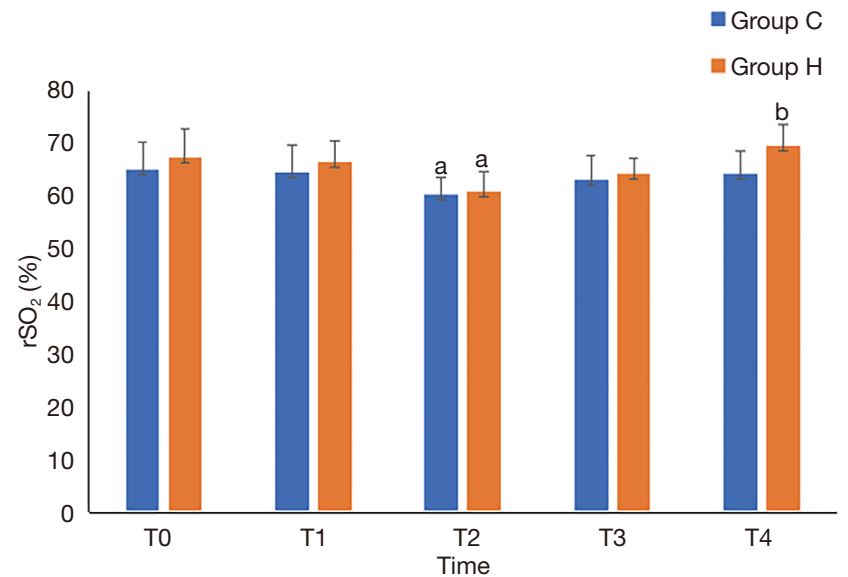

Figure 1 Differences in $\mathrm{rSO}_{2}$ between the two groups. ${ }^{a}, \mathrm{P}<0.05$ compared to T0; ${ }^{\text {b }}, \mathrm{P}<0.05$ compared to Group C. $\mathrm{rSO}_{2}$, regional cerebral oxygen saturation.

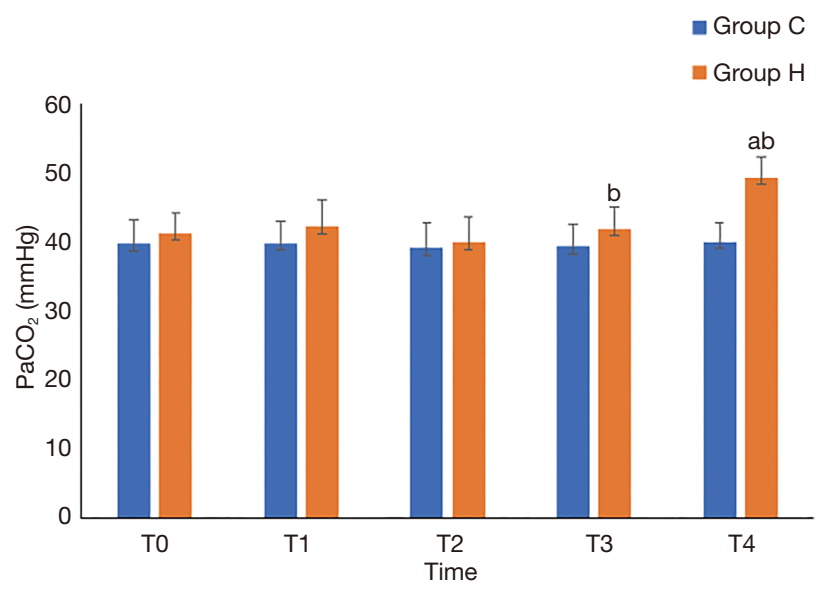

Figure 2 Differences in $\mathrm{PaCO}_{2}$ between the two groups. ${ }^{\text {a }}, \mathrm{P}<0.05$ compared to T0; ${ }^{\text {b }}, \mathrm{P}<0.05$ compared to Group C. $\mathrm{PaCO}_{2}$, partial pressure of carbon dioxide.

(Table 5).

\section{Discussion}

Cardiac valvular disease is a common clinical disease, valve replacement is the main surgical treatment of heart valve disease, its indications mainly have the following categories: heart valve serious diseases, such as valve stenosis or closed incomplete; the postoperative complications of degenerative valvular disease in the elderly; the possible complications include: low cardiac output syndrome;

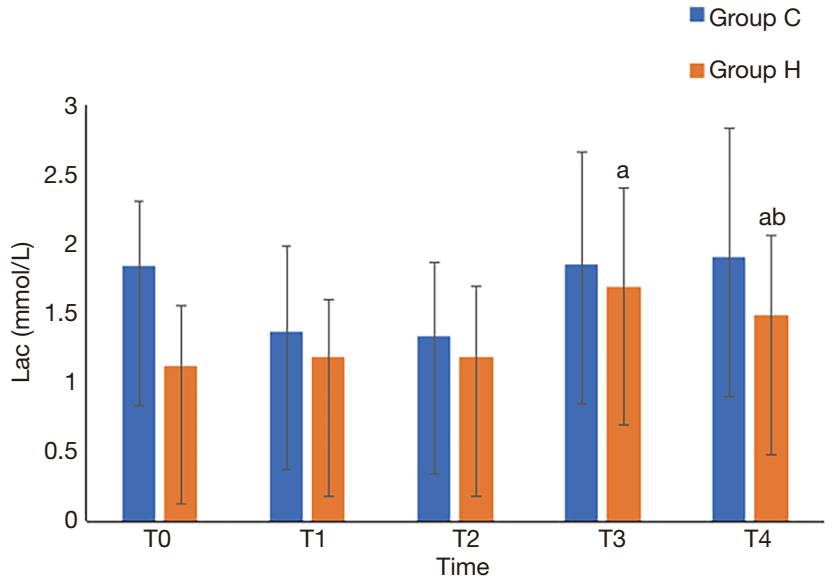

Figure 3 Differences in Lac between the two groups. ${ }^{a}, \mathrm{P}<0.05$ compared to T0; ${ }^{\text {b }}, \mathrm{P}<0.05$ compared to Group C. Lac,lactic acid.

severe arrhythmia; postoperative infection; perivalvular leakage of artificial valves. Many factors can cause lung injury in cardiac surgery, including general anesthesia, $\mathrm{CPB}$, and intrathoracic surgical procedures. Under these circumstances, a lung-protective ventilation strategy is believed to play a critical role in lung protection, and it can reduce postoperative complications, increase safety, and accelerate recovery. Lung-protective ventilation strategies have received extensive attention from anesthesiologists. PHC is an important lung-protective ventilation strategy, as it not only increases $\mathrm{PaCO}_{2}$ within an acceptable range, reduces tidal volume, "allows" hypercapnia, and prevents lung damage from high tension but also has protective and anti-inflammatory effects on the heart, nervous system, and many other organs $(5,6)$. A previous study (7) showed that mild hypercapnia $\left(\mathrm{PaCO}_{2}\right.$ at $\left.45-55 \mathrm{mmHg}\right)$ increased $\mathrm{rSO}_{2}$, improved cerebral oxygenation, and reduced the incidence of POCD. The decrease in intraoperative $\mathrm{rSO}_{2}$ is significantly associated with early POCD. Therefore, this study applied a lung-protective ventilation strategy to patients undergoing CVR and investigated the impact of $\mathrm{PHC}$ on $\mathrm{rSO}_{2}$ and postoperative cognitive function of patients.

NIRS is a novel $\mathrm{rSO}_{2}$ monitoring method that enables real-time, continuous, noninvasive monitoring of the oxygenation and metabolism of the brain tissue. This method is not affected by nonpulsatile blood flow, low temperature, or other factors, and it has been extensively applied in anesthesia for cardiac surgery (8). Frogel et al. (9) believed that monitoring cerebral oxygen saturation during 
Table 4 Comparison of MMSE scores between the two groups at each time point $(n=33, \bar{x} \pm s)$

\begin{tabular}{lcccc}
\hline Group & $\mathrm{n}$ & $1 \mathrm{~d}$ before surgery & $24 \mathrm{~h}$ after surgery & $7 \mathrm{~d}$ after surgery \\
\hline Group C & 33 & $27.82 \pm 1.98$ & $24.58 \pm 1.84^{\mathrm{a}}$ & $27.33 \pm 2.19$ \\
Group H & 33 & $27.94 \pm 1.32$ & $25.42 \pm 1.58^{\mathrm{ab}}$ & $27.67 \pm 1.69$ \\
\hline
\end{tabular}

a, $\mathrm{P}<0.05$ compared to T0; ${ }^{\mathrm{b}}, \mathrm{P}<0.05$ compared to Group C. MMSE, Mini-Mental State Examination.

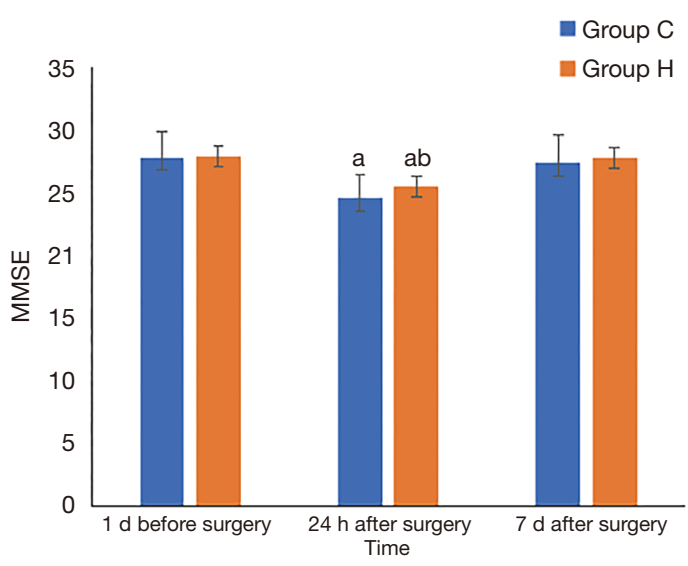

Figure 4 Comparison of MMSE score between the two groups at each time point. ${ }^{\text {a }}, \mathrm{P}<0.05$ compared to T0; ${ }^{\text {b }}, \mathrm{P}<0.05$ compared to Group C. MMSE, Mini-Mental State Examination.

Table 5 The incidence of POCD in the two groups ( $n=33, \eta / \%)$

\begin{tabular}{lccc}
\hline Group & $\mathrm{n}$ & $24 \mathrm{~h}$ after surgery & 7 d after surgery \\
\hline Group C & 33 & $17(51.5 \%)$ & $4(12.1 \%)^{\mathrm{a}}$ \\
Group H & 33 & $14(44.4 \%)^{\mathrm{b}}$ & $4(12.1 \%)^{\mathrm{a}}$ \\
\hline
\end{tabular}

${ }^{\mathrm{a}}, \mathrm{P}<0.05$ compared to T0; ${ }^{\mathrm{b}}, \mathrm{P}<0.05$ compared to Group $\mathrm{C}$. POCD, postoperative cognitive dysfunction.

cardiac surgery can indirectly reflect the status of brain tissue perfusion, and effective monitoring can guide the implementation of intraoperative brain protection measures. $\mathrm{rSO}_{2}$ monitoring can effectively prevent cardiac surgeryrelated POCD, since insufficient brain oxygen supply during surgery is one of the causes of POCD $(10,11)$. As a sensitive indicator of cerebral oxygen metabolism, $\mathrm{rSO}_{2}$ can monitor cerebral ischemia and hypoxia in real time and predict the risk of POCD after cardiac surgery. Using $\mathrm{rSO}_{2}$ to guide intraoperative management can improve the prognosis of patients undergoing surgery. It is generally believed that the normal baseline $\mathrm{rSO}_{2}$ among patients undergoing cardiac surgery is approximately 66\% (12). Patients are diagnosed with cerebral hypoxia if intraoperative $\mathrm{rSO}_{2}$ is less than
$50 \%$ or decreases more than $20 \%$ from the baseline for 1 min or more (13). Under these circumstances, clinicians should intervene promptly to prevent damage to the CNS. In this study, the MAP was maintained at $60-80 \mathrm{mmHg}$ in all patients, which ensured effective cerebral perfusion. Compared to the $\mathrm{rSO}_{2}$ at $\mathrm{T0}$ (before the surgery), the $\mathrm{rSO}_{2}$ in both groups dropped significantly during $\mathrm{CPB}(\mathrm{P}<0.05)$. The $\mathrm{rSO}_{2}$ of three patients decreased more than $20 \%$ compared to the baseline in a short period (one patients in Group $\mathrm{C}$ and two patients in Group $\mathrm{H}$ ), but it was returned to normal range by $\mathrm{CPB}$ and increasing the perfusion pressure promptly. At the postoperative 7-d follow-up of these three patients, no significant damage to the CNS or reduction in cognitive function were detected. The intraoperative reduction in $\mathrm{rSO}_{2}$ may be related to blood dilution due to CPB.

The results of this study showed that the Hb level was significantly lower than the preoperative level at each time point after CPB. Excluding the impacts of other relevant factors, blood dilution during $\mathrm{CPB}$ causes reductions in hematocrit and $\mathrm{Hb}$, and insufficient blood oxygen-carrying capacity directly lowers the oxygen supply to the brain tissue. Here, Group $\mathrm{H}$ had a significantly higher $\mathrm{rSO}_{2}$ $(\mathrm{P}<0.05)$, indicating that $\mathrm{PHC}$ is conducive to improving the autoregulation of the cerebral blood flow and the cerebral oxygen supply/consumption balance, which is consistent with a previous study (7). The reason may be that since $\mathrm{CO}_{2}$ is the most effective regulator of cerebral blood flow, the $\mathrm{PHC}$ ventilation strategy in the patients undergoing CVR increases $\mathrm{PaCO}_{2}$, catalyzes the activity of neuronal nitric oxide synthase, increases nitric oxide production, causes the expansion of cerebral blood vessels, and increases cerebral blood flow and cerebral oxygen supply, thereby reducing the risk of cerebral ischemia and hypoxia and effectively protecting brain function (14).

POCD is characterized by changes in perception, recognition, thinking, and memory after anesthesia or surgery. It mainly manifests as a continuous decline in cognitive function and the occurrence of mental confusion, anxiety, personality changes, and memory impairment, 
accompanied by lower social activity. A previous study (15) reported that at one week after cardiac surgery, $53 \%$ of the patients showed POCD. There are a variety of methods to assess postoperative cognitive function. As the main tool for cognitive decline screening, MMSE has high specificity and sensitivity and is appropriate for the assessment of cognitive function after cardiac surgery. Both of our groups had significantly lower MMSE scores $24 \mathrm{~h}$ after than before surgery $(\mathrm{P}<0.05)$ though the MMSE scores $7 \mathrm{~d}$ after surgery were not significantly different, indicating that the early POCD may be mainly caused by anesthetics, surgical stress and postoperative analgesia. At $7 \mathrm{~d}$ after surgery, the cognitive function of our patients had returned to the level before surgery.

In cardiac surgery, the incidence of POCD is impacted by multiple factors, including age, previous diseases, anesthetics, intraoperative hypothermia, cerebrovascular insufficiency, cerebral embolism, and systemic inflammation. Currently, age is believed to be the main factor for the occurrence of POCD (16). No significant differences were detected in the age, body weight, BSA, NYHA, nasopharyngeal temperature, blood glucose, ACCT, CPB duration, or surgery duration between our two groups. Keeping the CSI (anesthetic depth) at 4060 during surgery reduced the influence of objective external factors on the results. The decreased MMSE scores at $24 \mathrm{~h}$ but normal MMSE scores at $7 \mathrm{~d}$ suggest that early POCD may be mainly caused by multiple factors, including anesthetics, surgical stress, postoperative analgesia, and the use of analgesic drugs. Group $\mathrm{H}$ had a significantly higher MMSE score at $24 \mathrm{~h}$ after surgery than Group $\mathrm{C}(\mathrm{P}<0.05)$, and the two groups' scores at $7 \mathrm{~d}$ were not significantly different. These results indicate the PHC can help improve early POCD. The underlying mechanism may be that hypercapnia can reduce intracellular $\mathrm{pH}$, promote the oxidative utilization of glucose by increasing the concentration of adenosine and adenosine triphosphate, and maintain the reserve of energy-rich phosphoric acid in the brain tissue, thus protecting the brain and reducing the incidence of POCD.

Many studies on POCD are from large centers with large sample sizes. The limitations of this study are that the sample size was relatively small, and long-term follow-up data were not available. In the future, biomarkers related to cognitive impairment can be included to more deeply investigate the impact of the $\mathrm{PHC}$ ventilation strategy on $\mathrm{rSO}_{2}$ and POCD.

In summary, this study showed that PHC can increase
$\mathrm{rSO}_{2}$ and improve cerebral blood flow and the cerebral oxygen supply/consumption balance in patients undergoing CVR, thus having a brain protection effect. However, a significant effect of PHC on the incidence of POCD was not found in this study.

\section{Acknowledgments}

Funding: None.

\section{Footnote}

Reporting Checklist: The authors have completed the CONSORT reporting checklist. Available at http://dx.doi. org/10.21037/apm-20-2090

Data Sharing Statement: Available at http://dx.doi. org/10.21037/apm-20-2090

Conflicts of Interest: All authors have completed the ICMJE uniform disclosure form (available at http://dx.doi. org/10.21037/apm-20-2090). The authors have no conflicts of interest to declare.

Ethical Statement: The authors are accountable for all aspects of the work in ensuring that questions related to the accuracy or integrity of any part of the work are appropriately investigated and resolved. The study conformed to the provisions of the Declaration of Helsinki (as revised in 2013). This study was approved by the ethics committee of our hospital (No. kssy2019-30). Each patient understood this study and voluntarily signed an informed consent form.

Open Access Statement: This is an Open Access article distributed in accordance with the Creative Commons Attribution-NonCommercial-NoDerivs 4.0 International License (CC BY-NC-ND 4.0), which permits the noncommercial replication and distribution of the article with the strict proviso that no changes or edits are made and the original work is properly cited (including links to both the formal publication through the relevant DOI and the license). See: https://creativecommons.org/licenses/by-nc-nd/4.0/.

\section{References}

1. Holmgaard F, Vedel AG, Rasmussen LS, et al. The association between postoperative cognitive dysfunction 
and cerebral oximetry during cardiac surgery: a secondary analysis of a randomised trial. Br J Anaesth 2019;123:196-205.

2. Contreras M, Masterson C, Laffey JG. Permissive hypercapnia: what to remember. Curr Opin Anaesthesiol 2015;28:26-37.

3. Li L, Geng L, Ma C, et al. Effect of permissible hypercapnia on cognitive function after carotid endarterectomy. Int J Anesth Resus 2019;40:1051-5.

4. Chan MJ, Chung T, Glassford NJ, et al. Near-Infrared Spectroscopy in Adult Cardiac Surgery Patients: A Systematic Review and Meta-Analysis. J Cardiothorac Vasc Anesth 2017;31:1155-65.

5. Hummler HD, Banke K, Wolfson MR, et al. The Effects of Lung Protective Ventilation or Hypercapnic Acidosis on Gas Exchange and Lung Injury in Surfactant Deficient Rabbits. PLoS One 2016;11:e0147807.

6. He M, Chen Y. Effects of permissive hypercapnia on lung function and reaction to collapsed pneumonia after one-lung ventilation. Journal of Clinical Anesthesiology 2015;(12):1172-5.

7. Wong C, Churilov L, Cowie D, et al. Randomised controlled trial to investigate the relationship between mild hypercapnia and cerebral oxygen saturation in patients undergoing major surgery. BMJ Open 2020;10:e029159.

8. Sørensen H. Near infrared spectroscopy evaluated cerebral oxygenation during anesthesia. Dan Med J 2016;63:B5318.

9. Frogel J, Kogan A, Augoustides JGT, et al. The Value

Cite this article as: Zhu L, Shi H, Zhu C, Liu H, Su Z, Zhao Y. Impact of permissive hypercapnia on regional cerebral oxygen saturation and postoperative cognitive function in patients undergoing cardiac valve replacement. Ann Palliat Med 2020;9(6):4066-4073. doi: 10.21037/apm-20-2090 of Cerebral Oximetry Monitoring in Cardiac Surgery: Challenges and Solutions in Adult and Pediatric Practice. J Cardiothorac Vasc Anesth 2019;33:1778-84.

10. Murniece S, Soehle M, Vanags I, et al. Near Infrared Spectroscopy Based Clinical Algorithm Applicability During Spinal Neurosurgery and Postoperative Cognitive Disturbances. Medicina (Kaunas) 2019;5 5:179.

11. Ortega-Loubon C, Herrera-Gómez F, Bernuy-Guevara C, et al. Near-Infrared Spectroscopy Monitoring in Cardiac and Noncardiac Surgery: Pairwise and Network MetaAnalyses. J Clin Med 2019;8:2208.

12. Deschamps A, Hall R, Grocott H, et al. Cerebral Oximetry Monitoring to Maintain Normal Cerebral Oxygen Saturation during High-risk Cardiac Surgery: A Randomized Controlled Feasibility Trial. Anesthesiology 2016;124:826-36.

13. Kumpaitiene B, Svagzdiene M, Drigotiene I, et al. Correlation among decreased regional cerebral oxygen saturation, blood levels of brain injury biomarkers, and cognitive disorder. J Int Med Res 2018;46:3621-9.

14. Nayak S, Jindal A. Permissive hypercapnia: Is there any upper limit? Indian J Crit Care Med 2015;19:56-7.

15. Glumac S, Kardum G, Karanovic N. Postoperative Cognitive Decline After Cardiac Surgery: A Narrative Review of Current Knowledge in 2019. Med Sci Monit 2019;25:3262-70.

16. Jungwirth B, Zieglgänsberger $W$, Kochs E, et al. Anesthesia and postoperative cognitive dysfunction (POCD). Mini Rev Med Chem 2009;9:1568-79. 